\title{
A survey of heterobasidiomycetous yeasts for the presence of the genes homologous to virulence factors of Filobasidiella neoformans, CNLAC1 and CAP59
}

\author{
R. Petter, ${ }^{1}$ B. S. Kang, ${ }^{1}$ T. Boekhout, ${ }^{2}$ B. J. Davis ${ }^{1}$ and K. J. Kwon-Chung ${ }^{1}$
}

Author for correspondence: K. J. Kwon-Chung. Tel: +1 301496 1602. Fax: +1 3014021003. e-mail: june_kwon-chung@nih.gov

1 Molecular Microbiology Section, Laboratory of Clinical Investigation, NIAID, Building 10, 11C304, NIH, Bethesda, MD 20892, USA

2 Centraalbureau voor Schimmelcultures, Utrecht, The Netherlands

\begin{abstract}
Among species of the heterobasidiomycetous yeasts, Filobasidiella neoformans is the only serious pathogen that causes fatal infections in both immunocompromised as well as immunocompetent patients. Three phenotypic characteristics, including growth at $37^{\circ} \mathrm{C}$, extracellular polysaccharide capsule and laccase activity, of $F$. neoformans are known to play major roles in the pathogenicity of the fungus. Several CAP genes involved in polysaccharide capsule formation, as well as the CNLAC1 gene encoding a laccase, have previously been cloned and characterized. To analyse the presence of these Cryptococcus neoformans virulence factors in other heterobasidiomycetous yeasts, numerous species of heterobasidiomycetous yeasts were screened for the presence of laccase activity and a polysaccharide capsule. Species exhibiting laccase activity and possessing a glucuronoxylomannan (GXM) capsule were screened for homologues of both the CAP59 gene and the CNLAC1 gene of $F$. neoformans. Southern blots of genomic DNA from GXM capsule-producing species exhibited no discernible hybridization to the CAP59 DNA sequence except for the two varieties of $F$. neoformans and Cryptococcus podzolicus. Although discernible, the hybridization band observed with the DNA of $C$. podzolicus was faint. Oligonucleotide primers constructed using the CAP59 gene sequence also failed to yield PCR products from DNAs of these yeasts except for the two varieties of $F$. neoformans. These results, coupled with the absence of a CAP59 homologue in the database, suggested the CAP59 gene to be unique to $F$. neoformans. $C$. podzolicus was the only species besides $F$. neoformans that possessed a capsule and expressed strong laccase activity on various media containing phenolic compounds. A CNLAC1 homologue was isolated from $C$. podzolicus while it was not detected in the species producing beige to faint tan colonies on media with phenolic compounds. Compared to the CNLAC1 sequence of four serotypes of $F$. neoformans, the CNLAC1 homologue of $C$. podzolicus showed the highest homology to that of serotype $B / C$ strains and the lowest homology to that of serotype A strains.
\end{abstract}

Keywords: Cryptococcus neoformans, virulence gene homologues, basidiomycetous yeasts

\section{INTRODUCTION}

\section{Filobasidiella neoformans Kwon-Chung [anamorph}

Abbreviations: DOPA, 3,4-dihydroxyphenylalanine; GXM, glucuronoxylomannan; ITS, internal spacer region.

The GenBank accession numbers for the sequences determined in this work are AF337642, L22866, AF337643, AF337644 and AF337645.
Cryptococcus neoformans (Sanfelice )Vuillemin] is a heterobasidiomycetous yeast which causes fatal meningoencephalitis mostly in immunocompromised patients. The two varieties of $F$. neoformans can be identified based on their serotypes: F. neoformans var. neoformans (serotype A/D) and F. neoformans var. bacillispora (serotype B/C). As evident from phylogenetic trees constructed on the basis of small- and 
large-subunit rRNA sequences, the family Filobasidiaceae is polyphyletic and F. neoformans is more closely related to members of the Tremellaceae than to other members of the Filobasidiaceae (Swann \& Taylor, 1993; Kwon-Chung et al., 1995). These observations suggest a proximal evolution of Filobasidiella and members of the Tremellaceae and, consequently, $F$. neoformans should be classified under Tremellales rather than Filobasidiales (Kwon-Chung et al., 1995; Fell et al., 2000). As in the case of F. neoformans, anamorphs of most members of Tremellaceae are capsulated budding yeasts (Oberwinkler, 1987). The polysaccharide capsule of $C$. neoformans is mainly composed of glucuronoxylomannan (GXM), a linear $\alpha$ 1,3-linked mannan bearing 6-O-acetyl groups and monosaccharide side chains of xylose and glucuronic acid (Battacharjee et al., 1978; Cherniak et al., 1988). The GXM of polysaccharides isolated from Filobasidium species (C. albidus var. albidus) is reported to have a structural resemblance to that of $F$. neoformans (Ikeda et al., 1991). The major capsular polysaccharide from Tremella mesenterica is also GXM with some variation: the xylose side chain is composed of multimers instead of monomer (Slodki, 1966). The polysaccharide capsule is known as a primary virulence factor of $F$. neoformans. Four genes, CAP59, CAP64, CAP60 and CAP10, involved in capsule formation in F. neoformans have been identified and the loss of any of the four genes was found to result in a loss of capsule and virulence (Chang \& Kwon-Chung, 1994, 1998, 1999; Chang et al., 1996). The CAP59 genes have been isolated from several strains of each serotype and the sequence comparison indicated $>90 \%$ similarity between different serotypes (Nakamura et al., 2000). Unlike other pathogenic yeasts, $F$. neoformans produces melanin when grown on media containing diphenolic compounds (Staib, 1962; Polacheck et al., 1982; Williamson, 1994). Melaninforming ability in this species was shown to play an important role in virulence (Kwon-Chung et al., 1982; Rhodes et al., 1982) and the CNLAC1 gene product responsible for the formation of melanin was identified as a laccase (Williamson, 1994). Disruption of CNLAC1 in a serotype $D$ strain significantly prolonged the survival of infected mice (Salas et al., 1996), confirming the role of melanin formation in the virulence of $F$. neoformans. Though haploid cells (yeast cells) of Tremella species lack the ability to produce melanin, basidiocarps of several Tremella species, such as $T$. foliacea and $T$. subanomala, are pigmented. However, T. mesenterica showed weak laccase and aryl-alcohol oxidase activity (Peláez et al., 1995).

To determine the phylogenetics of virulence factors in $F$. neoformans, we screened various heterobasidiomycetous species for the ability to produce melanin and polysaccharide capsules. The genomic DNAs of species positive for both of these phenotypes were screened for sequences homologous to the CAP59 and the CNLC1 genes. Sequences homologous to CAP59 were not detected in any heterobasidiomycetous genera that are known to produce GXM capsules. Cryptococcus pod- zolicus was found to be the only species containing a sequence homologous to CNLAC1. We obtained sequences from conserved regions of the CNLAC1 homologue from C. podzolicus and compared them with sequences from strains of four $F$. neoformans serotypes.

\section{METHODS}

Strains. Table 1 lists the number of strains in each genus screened for the production of melanin. Table 2 summarizes the species (excluding members of the genera Filobasidiella and Cryptococcus) that reacted with either 3,4-dihydroxyphenylalanine (DOPA) or norepinephrine. Melanin-forming strains were tested for capsule production as described below.

Media and growth conditions. Yeast cultures were maintained on YEPD ( $1 \%$ yeast extract, $2 \%$ peptone, $2 \%$ glucose) agar slants and grown in the same medium, depending on strains, at either $30^{\circ} \mathrm{C}$ or $25^{\circ} \mathrm{C}$. Escherichia coli was grown in Luria-Bertani broth or on agar supplemented with $150 \mu \mathrm{g}$ ampicillin $\mathrm{ml}^{-1}$. Electrocompetent E. coli cells (ElectroMAX DH10B, Gibco-BRL) were transformed by electroporation according to instructions supplied by the manufacturer (BioRad Laboratories).

Observation of polysaccharide capsule. A small loopful of cells, obtained from colonies grown on YEPD agar for $48 \mathrm{~h}$ at $25^{\circ} \mathrm{C}$ or $30^{\circ} \mathrm{C}$, were mounted on India ink to observe the polysaccharide capsule.

DOPA and norepinephrine agar assay for melanin-like pigment formation. Yeast cells were patched on DOPA and norepinephrine agar $(0.5 \mathrm{mM})$ and incubated for up to 2 weeks at $25^{\circ} \mathrm{C}$ or $30^{\circ} \mathrm{C}$ (Kwon-Chung et al., 1982). Production of light tan, brown to black pigment was regarded as positive for laccase activity and the cultures that tested positive

Table 1. Heterobasidiomycetous yeast genera tested for production of melanin-like pigment

\begin{tabular}{|lcc|}
\hline Genus & $\begin{array}{c}\text { No. of } \\
\text { species }\end{array}$ & $\begin{array}{c}\text { No. of } \\
\text { strains }\end{array}$ \\
\hline Bensingtonia & 3 & 3 \\
Bullera & 4 & 4 \\
Bulleromyces & 1 & 2 \\
Cryptococcus (non-neoformans) & 18 & 49 \\
Cystofilobasidium & 2 & 2 \\
Fibulobasidium & 1 & 2 \\
Filobasidiella & 1 & 157 \\
Filobasidium & 4 & 20 \\
Fellomyces & 1 & 1 \\
Holtermannia & 1 & 2 \\
Leucosporidium & 2 & 2 \\
Malassezia & 1 & 1 \\
Phaffia & 1 & 2 \\
Rhodotorula & 9 & 15 \\
Rhodosporidium & 5 & 5 \\
Sporidiobolus & 2 & 6 \\
Sporobolomyces & 5 \\
Tremella & 5 & 5 \\
Trichosporon & 5 & 14 \\
Trimorphomyces & 15 & 21 \\
Ustilago & 1 & 3 \\
\hline
\end{tabular}


Table 2. Heterobasidiomycetous yeasts (excluding the genera Filobasidiella and Cryptococcus) which produced beige to tan coloured colonies on DOPA and/or norepinephrine (NOR) agar

\begin{tabular}{|llcc|}
\hline Species & CBS no. & DOPA* NOR* \\
\hline Filobasidium floriforme & 6240,6241, & - & $\mathrm{f} / \mathrm{d}$ \\
& 6242,7634, & & \\
& 7635,7636 & & \\
F. capsuligenum & 4736 & - & $\mathrm{f} / \mathrm{d}$ \\
F. globisporum & 7642 & - & $\mathrm{f} / \mathrm{d}$ \\
F. uniguttulatum & 1727 & $\mathrm{f}$ & - \\
Holtermannia corniforme & 7088 & $\mathrm{f} / \mathrm{d}$ & - \\
Tremella encephala & 6968,8207, & $\mathrm{f}$ & $\mathrm{f} / \mathrm{d}$ \\
& 8217,8218, & & \\
& 8220,8235 & & \\
T. foliacea & 6969,7215, & $\mathrm{f}$ & $\mathrm{f} / \mathrm{v}$ \\
T. fusiformis & 6970,6971 & - & $\mathrm{f} / \mathrm{v}$ \\
T. globospora & 6972, & $\mathrm{f}$ & $\mathrm{f} / \mathrm{d}$ \\
T. subanomala & 6976 & $\mathrm{f}$ & $\mathrm{f} / \mathrm{d}$ \\
Trimorphomyces & 200.94 & $\mathrm{f}$ & - \\
papilionaceus & 443.92 & $\mathrm{f} / \mathrm{d}$ & $\mathrm{f} / \mathrm{d}$ \\
& 445.92 & $\mathrm{f} / \mathrm{d}$ & - \\
\hline
\end{tabular}

*f, faint; v, variable; d, delayed.

with both DOPA and norepinphrine were considered to be true laccase-positive.

DNA analysis. Rapid DNA preparation was as previously described (Fujimura \& Sakuma, 1993) and for larger quantities, the method described by Varma \& Kwon-Chung (1991) was used. For Southern analysis, DNA samples were digested with EcoRI and fractionated in agarose gels. DNA was transferred to Hybond-N nylon membranes and hybridized to labelled DNA probes using standard protocols. Random hexamer priming was used to label the DNA probes to specific activities $>10^{8}$ d.p.m. $\mu \mathrm{g}^{-1}$ (Feinberg $\&$ Vogelstein, 1983).

Polymerase chain reaction (PCR). PCRs were performed with the MJ Research thermocycler using Boehringer Mannheim's
Taq DNA polymerase and nucleotide mix, or PCR Supermix (Gibco-BRL). The amplification conditions used with each set of primers are described below.

Isolation of the CNLAC1 gene homologue. Two oligonucleotide primers (Table 3) compatible with the conserved copper-binding sites of CNLAC1 gene (Williamson, 1994) and the laccase genes of three Homobasidiomycete species (Mikuni \& Morohoshi, 1997; Perry et al., 1993; Giardina et al., 1995) were designed and used for in vitro amplification from B-3501 (serotype D strain). The PCR cycle was initiated by 4 min at $94{ }^{\circ} \mathrm{C}$, followed by 29 cycles of denaturation $\left(1 \mathrm{~min} ; 94^{\circ} \mathrm{C}\right)$, annealing $\left(1 \mathrm{~min} ; 50^{\circ} \mathrm{C}\right)$ and polymerization $\left(1 \mathrm{~min} ; 72^{\circ} \mathrm{C}\right)$. The reaction was terminated by an extended polymerization step $\left(10 \mathrm{~min} ; 72{ }^{\circ} \mathrm{C}\right)$. The CNLAC1 PCR product was used as the probe to isolate genomic fragments from a size-selected library. The CNLAC1 fragments obtained from a size-selected library of $F$. neoformans serotypes A ( $\mathrm{H} 99$, a reference strain widely used for molecular genetic study), B (B-3939, the type culture of C. neoformans var. gattii), C (NIH34, a serotype C reference strain used for production of rabbit anti-C serum), were each cloned into a Bluescript SK + vector (Stratagene) and subjected to nucleotide sequence analysis. The PCR fragment obtained from C. podzolicus (CBS 6442) was cloned into the same vector and sequenced.

Detection of CAP59 sequence. Genomic DNAs from strains producing a large GXM capsule were digested with various restriction enzymes and analysed by Southern hybridization under varying stringency conditions using the CAP59 cDNA probe obtained from strain B-3501 (serotype D) (Chang \& Kwon-Chung, 1994). Attempt was also made to amplify the sequence by PCR using primers derived from the CAP59 sequence of B-3501 (serotype D) (Table 3). The in vitro amplification procedure was the same as that for the CNLAC1.

Nucleotide sequence analysis. Nucleotide sequences were obtained using a Sequenase 2.0 kit (USB Cleveland) and the ABI PRISM (Perkin-Elmer) sequencer. Sequence analysis, comparisons and database searches were performed with MacVector 3.0 (Oxford Molecular Group) and various other programs of the Genetics Computer Group.

\section{RESULTS AND DISCUSSION}

\section{Laccase activity}

Numerous heterobasidiomycetous species belonging to 21 genera and having yeast anamorphs were screened

Table 3. Oligonucleotide primers used for the cloning of CNLAC1 and CAP59 homologues

\begin{tabular}{|c|c|c|}
\hline & Oligonucleotide sequence $\left(5^{\prime}-3^{\prime}\right)$ & Remarks \\
\hline & GACTAGAATTCGTATTGGTGGCACTTC & $\begin{array}{l}\text { CNLAC1 sense primer, derived from strain } \\
\text { B-3501 serotype D (Williamson, 1994) }\end{array}$ \\
\hline & GCTAAAAGCTTCGTGCAGGTGGTAAGG & $\begin{array}{l}\text { CNLAC1 antisense primer, derived from } \\
\text { strain B-3501 serotype D (Williamson, } \\
\text { 1994) }\end{array}$ \\
\hline & AGAATTCCACCAGGCATATTTCG & $\begin{array}{l}\text { CAP59 sense primer, derived from strain } \\
\text { B-3501 serotype D (Chang \& Kwon- } \\
\text { Chung, 1994) }\end{array}$ \\
\hline & ATCAAAGCTTGCAACGTCTCCATATCCTC & $\begin{array}{l}\text { CAP59 antisense primer, derived from } \\
\text { strain B-3501 serotype D (Chang \& } \\
\text { Kwon-Chung, 1994) }\end{array}$ \\
\hline
\end{tabular}


for formation of the melanin-like pigment on DOPA and norepinephrine media (Table 1). Of the two substrates, the latter was found to be superior in reproducibility, stability and specificity for laccase activity judged by the results obtained from $F$. neoformans strains. Table 2 lists the species belonging to four of the 21 genera, excluding Filobasidiella and Cryptococcus, that reacted with DOPA and norepinephrine. Although the intensity varied, all strains of $F$. neoformans produced melanin. Colony colour of the strains listed in Table 2, varied from beige to light tan ( $f$ for faint) and was not comparable to the dark brown to black colour of $F$. neoformans colonies. All the strains, other than $F$. neoformans, that exhibited strong laccase activity belonged to C. podzolicus (Table 4). Of the $15 \mathrm{C}$. podzolicus isolates tested, only the type strain (CBS 6819) was clearly laccase-negative and may harbour mutations in genes involved in melanin synthesis. All the laccase-positive isolates of C. podzolicus used in this study were isolated from soil and have previously been identified as C. laurentii. However, sequence studies of the D1/D2 domains of the large subunit and the internal transcribed spacer region (ITS) of rDNA clearly showed that they are C. podzolicus (T. Boekhout and others, unpublished).

\section{Isolation of CNLAC1 homologous sequences}

DNAs were prepared from representative strains of Filobasidium floriforme, F. uniguttulatum, Tremella. encephala, T. foliacea and T. globospora in addition to F. neoformans and C. podzolicus. Southern analysis was performed using an $800 \mathrm{bp}$ CNLAC1 cDNA probe (C. neoformans serotype D) (Williamson, 1994) under various stringency conditions. No detectable hybridization signals were observed with those species that produced beige to tan colonies on DOPA or norepinephrine medium. Low-stringency washes $(2 \times$ SSC: $0 \cdot 1 \%$ SDS, $20 \mathrm{~min}$, room temperature) and extended exposure for up to 2 weeks at $-70{ }^{\circ} \mathrm{C}$ still revealed no hybridization signals. Intense hybridization signals were observed with DNAs from strains of $F$. neoformans while those with varying intensity were detected with DNAs obtained from various C. podzolicus isolates. Southern hybridizations representing negative and positive results are shown in Fig. 1. Sizeselected genomic libraries were constructed to isolate conserved regions of the laccase gene from strains of $\mathrm{A}$, $\mathrm{B}$ and $\mathrm{C}$ serotypes of $F$. neoformans. PCR, using primers compatible with the conserved laccase copper-binding sites (Table 3), enabled the isolation of homologous sequences from C. podzolicus while the same primers failed to yield amplicons from species that produced beige to tan colonies. The PCR fragment of the CNLAC1 amplified from C. podzolicus CBS 6442 was sequenced in order to compare it with those of $F$. neoformans. Sequence comparisons of the conserved region indicated a high degree of similarity between the CNLAC1 fragments isolated from four F. neoformans strains and C. podzolicus CBS 6442. A pair-wise sequence com-
Table 4. Cryptococcus species (excluding C. neoformans) tested for the production of melanin-like pigment on DOPA or norepinephrine (NOR) agar

\begin{tabular}{|c|c|c|c|}
\hline Species & CBS no. & DOPA* & NOR* \\
\hline C. aerius & 155 & - & - \\
\hline \multirow[t]{3}{*}{ C. ater } & 4685 & - & - \\
\hline & 5809 & - & - \\
\hline & 5591 & - & - \\
\hline C. bhutanensis & 6294 & $\mathrm{f} / \mathrm{d}$ & - \\
\hline C. consortionis & 7159 & - & - \\
\hline C. dimennae & 5570 & - & - \\
\hline C. curvatus & 570 & - & - \\
\hline \multirow{2}{*}{ C. flavus } & 331 & - & - \\
\hline & 8296 & - & - \\
\hline C. friedmannii & 7160 & - & - \\
\hline C. heveanensis & 569 & - & - \\
\hline \multirow[t]{2}{*}{ C. humicolus } & 571 & - & - \\
\hline & 4281 & - & - \\
\hline C. hungaricus & 4214 & - & - \\
\hline \multirow[t]{13}{*}{ C. laurentii } & 139 & - & $\mathrm{f} / \mathrm{d}$ \\
\hline & 973 & - & - \\
\hline & 2174 & - & - \\
\hline & 5746 & - & - \\
\hline & 4919 & - & - \\
\hline & 6473 & - & $\mathrm{d}$ \\
\hline & 6474 & - & - \\
\hline & 6475 & - & - \\
\hline & 6476 & - & - \\
\hline & 7140 & - & - \\
\hline & 7235 & - & - \\
\hline & 8359 & - & - \\
\hline & 8360 & - & - \\
\hline C. macerans & 2206 & - & - \\
\hline C. magnus & 140 & - & - \\
\hline C. penaeus & 2409 & - & - \\
\hline \multirow[t]{15}{*}{ C. podzolicus } & 6819 & - & - \\
\hline & 7717 & - & $\mathrm{d}$ \\
\hline & 6442 & + & + \\
\hline & 6445 & + & + \\
\hline & 6446 & + & + \\
\hline & 6484 & + & + \\
\hline & 6485 & $\mathrm{f}$ & + \\
\hline & 6486 & + & + \\
\hline & 6487 & + & + \\
\hline & 6488 & + & + \\
\hline & 6490 & + & + \\
\hline & 6492 & $\mathrm{f}$ & + \\
\hline & 6493 & + & + \\
\hline & 6494 & + & + \\
\hline & 6496 & + & + \\
\hline C. terreus & 1895 & - & $\mathrm{f} / \mathrm{d}$ \\
\hline \multirow[t]{2}{*}{ C. vishniacii } & 8142 & - & - \\
\hline & 8143 & - & $\mathrm{f} / \mathrm{d}$ \\
\hline
\end{tabular}

$* f$, faint; $d$, delayed.

parison was performed between C. podzolicus, the strains of four F. neoformans serotypes and three species of Homobasidiomycetes: Pleurotus ostreatus (Giardina 


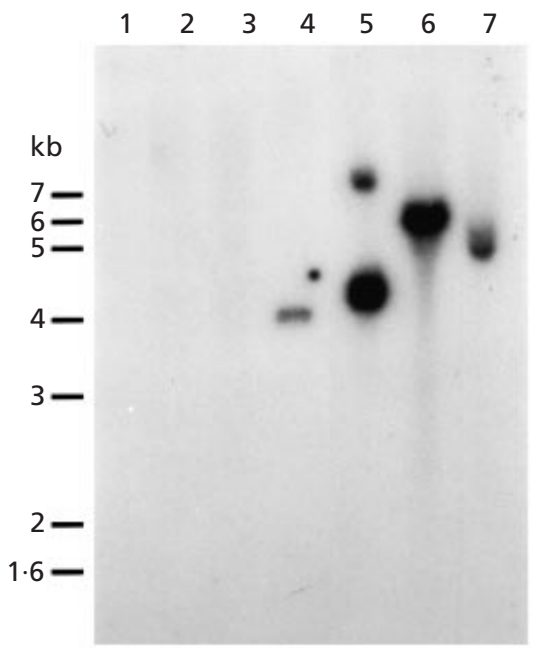

Fig. 1. Southern blot hybridization of genomic DNAs obtained from various species of heterobasidiomycetous yeasts with the CNLAC1 CDNA probe of B-3501. Lane 1, T. globospora (CBS 6972); lane 2, T. foliacea (CBS 6969); lane 3, T. encephala (CBS 8207); lane 4, C. podzolicus (CBS 6442); lane 5, F. neoformans var. neoformans (B-3501); lane 6, F. neoformans var. neoformans (H99); lane 7, F. neoformans var. bacillispora (NIH34). The hybridization and washes were performed under low-stringency conditions $\left(45^{\circ} \mathrm{C} ; 2 \times \mathrm{SSC} / 0.1 \% \mathrm{SDS}\right)$ and the filter was exposed for $7 \mathrm{~d}$ at $-70^{\circ} \mathrm{C}$.

et al., 1995), Coriolus versicolor (Mikuni \& Morohoshi, 1997) and Agaricus bisporus (Perry et al., 1993). It revealed the highest homology ( $94 \%$ ) between strains of serotype $\mathrm{B}$ and $\mathrm{C}$ followed by serotype $\mathrm{B} / \mathrm{C}$ and $\mathrm{C}$. podzolicus (92\%), serotype B/C and serotype D (82\%), serotype A and serotype D $(70 \%)$, serotype A and serotype C (68\%), serotype A and serotype B (67\%), and serotype A and C.podzolicus (67\%). The sequences of the copper-binding region conserved in three species of Homobasidiomycetes were considerably diverged from those of C. podzolicus and F. neoformans ( $\%$ homology less than $37 \%$ ) (Fig. 2). The higher homology observed between sequences of serotype $\mathrm{D}$ and serotypes $\mathrm{B} / \mathrm{C}$ compared to that between serotypes $\mathrm{D}$ and $\mathrm{A}$ was unexpected since it was not the case with either the partial gene sequence of CAP59 (Nakamura et al., 2000) or the sequence of a PCR fragment $(462 \mathrm{bp})$ amplified from a region of CNLAC1 gene partially overlapping with ours in different strains of serotype B (Xu et al., 2000). However, a closer genetic relationship of serotype D to serotype B strains than to serotype A isolates of $F$. neoformans has been observed when partial largesubunit rRNA sequence was analysed (Gueho et al., 1993). Franzot et al. (1999) also observed significant differences in URA5 sequences and the DNA fingerprinting patterns between strains of serotype A and D and indicated that serotype A strains warrant a separate varietal status: C. neoformans var. grubii. Subsequent analysis of other genetic markers, such as the intergenic spacer sequence associated with rDNA or amplified fragment length polymorphisms, however, did not support a separate varietal status for serotype A (Diaz et

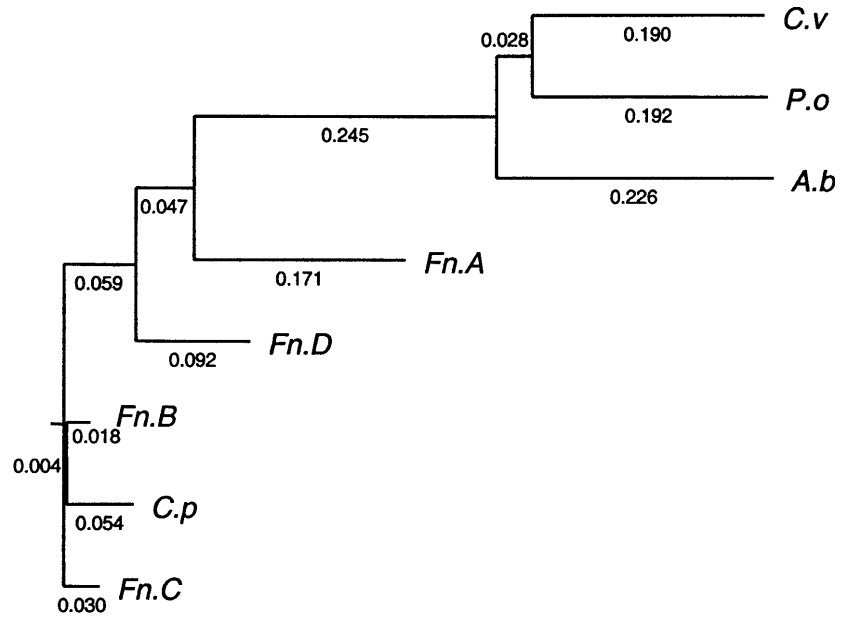

Fig. 2. Dendrogram derived from conserved sequence comparison using the CLUSTER W ALIGNMENT program. $A . b, A$. bisporus (GenBank accession L10063), P.o, Pleorotus ostreatus (GenBank accession Z34847), C.v, Coriolus versicolor (EMBL D284235). GenBank accession numbers of the four $F$. neoformans serotypes and C. podzolicus are: Fn.A, AF337642; Fn.D, L22866; Fn.B, AF337643; Fn.C, AF337644; C.p, AF337645. The numbers on the branches of the dendrogram indicate changes per residue.

al., 2000; Boekhout et al., 2001). These findings indicate that the phylogenetic relationship between strains based on a single gene sequence can vary depending on the strains of $F$. neoformans used and hence can lead to confusing results. They also indicate the existence of considerable genetic heterogeneity among strains of the same serotype of $F$. neoformans.

\section{The CAP59 homologues were not detected in the genomes of GXM polysaccharide capsule forming yeasts other than various strains of $F$. neoformans}

Of the yeasts listed in Table 1, large polysaccharide capsules were observed in species of Filobasidiella, Cryptococcus, Bulleromyces, Bullera, Filobasidium, Tremella and Trimorphomyces. The species forming large capsules mostly belonged to the Tremellales and Filobasidiales (Fell et al., 2000). Since the major polysaccharide produced by species of Filobasidiella, Filobasidium, Tremella and Cryptococcus is known to be GXM (Abercombie et al., 1960; Cherniak et al., 1988; Ikeda et al., 1991; Slodki, 1966), we assumed that the genes involved in polysaccharide formation were conserved among these yeasts. It was expected, therefore, that Southern blot analysis would detect the DNA sequences which hybridize to the CAP59 cDNA probe of serotype D from $F$. neoformans. An intense signal was observed for all four serotypes of $F$. neoformans. Southern blot analysis of genomic DNAs from species of Tremella, Filobasidium and Cryptococcus, however, showed a faint or no signal even under conditions of low stringency and prolonged exposure $(7 \mathrm{~d})$ at $-70{ }^{\circ} \mathrm{C}$. Southern blot analysis of DNAs from selected strains of 


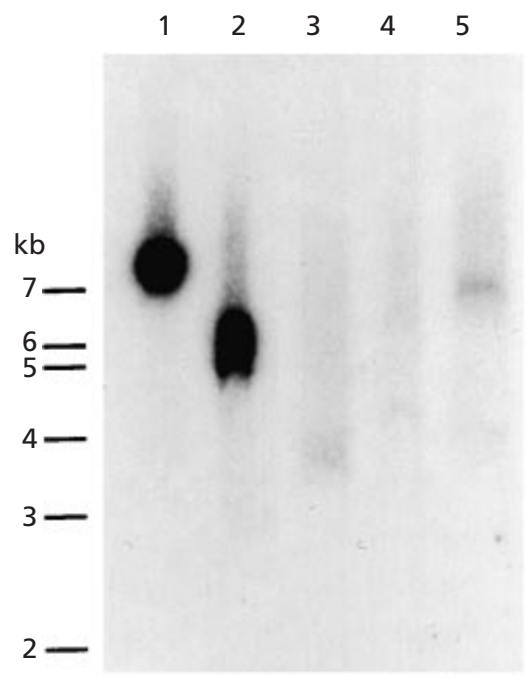

Fig. 3. Southern blot hybridization of genomic DNAs obtained from various species of Heterobasidiomycetes probed with radiolabelled CAP59 CDNA of B-3501 (serotype D). Lane 1, F. neoformans var. neoformans (B-3501, serotype D); lane 2, F. neoformans var. bacillispora (NIH34, serotype C); lane 3, Tremella foliacea (CBS 6969); lane 4, Filobasidium uniguttulatum (CBS 1727); lane 5, C. podzolicus (CBS 6442). Experimental conditions were the same as those for the CNLAC1 probe.

F. neoformans serotype A, F. neoformans serotype C, Tremella foliacea, Filobasidium uniguttulatum and Cryptococcus podzolicus is shown in Fig. 3. Besides F. neoformans, only Cryptococcus podzolicus (CBS 6474) showed a signal but it was extremely faint. While a faint hybridization signal was obtained with C. podzolicus DNA under low-stringency conditions, PCR primers 3 and 4 (Table 3 ) that effectively amplify the CAP59 sequence from all four serotypes of $F$. neoformans failed to generate any product. This suggested that the signal with C. podzolicus DNA was probably the result of nonspecific hybridization due to low stringency conditions. These yeasts may have functional homologues of CAP59 that have little nucleotide sequence similarity. The other explanation may be that the CAP59 pathway in $F$. neoformans is not conserved in other basidiomycetous yeasts. Though the function of CAP59 in $F$. neoformans is unknown, the presence of a transmembrane domain suggests it to be involved in secretion (Chang \& Kwon-Chung, 1994).

\section{Tremella lineage of CNLAC1 among the capsulated yeasts}

Although the DNA sequence of the laccase gene in C. podzolicus shows high homology to that of $F$. neoformans, a phylogenetic tree constructed by Fell et al. (2000) on the large rDNA subunit did not show them to be in the same cluster. Both C. podzolicus and F. neoformans, however, were in the Tremellales clade of the hymenomycetous yeasts (Fell et al., 2000). This suggests that CNLAC1 has evolved independently and is preserved in multiple internal clusters among species with the Tremella lineage and thus the sequence is inappropriate for the construction of phylogenetic trees. Considering the higher than $90 \%$ sequence homology between F. neoformans and C. podzolicus, it is likely that the CNLAC1 homologues of these two species have originated from a common ancestor. The lack of CNLAC1 homologue in Tremella species that produced faintly brown colonies on DOPA or norepinephrine agar, such as $T$. foliacea and $T$. encephala, was unexpected. It is possible that these Tremella species possess a laccase gene that has undergone enough genetic drift not to be detected by Southern hybridizations or PCR techniques. The laccase gene sequences of homobasidiomycetous species showed no close relationship with those of F. neoformans and C. podzolicus (Fig. 2).

\section{Uniqueness of $\boldsymbol{F}$. neoformans among tremellaceous yeasts}

F. neoformans possesses distinct features among members of the Tremellales. It is the only yeast in this order that produces a slender capitate holobasidium with basipetally formed chains of basidiospores (KwonChung, 1975) and it is the only species to cause a systemic fatal infection in humans. As far as we know, it is the only species of the Tremellales that grows optimally at temperatures above $30{ }^{\circ} \mathrm{C}$. The optimum and maximum temperatures for growth of $F$. neoformans are $32{ }^{\circ} \mathrm{C}$ and $40^{\circ} \mathrm{C}$ respectively (KwonChung \& Bennett, 1992). Some of the melanin-forming strains of Cryptococcus species isolated from clinical specimens and identified as C. laurentii may have been C. podzolicus; the aetiological significance of Cryptococcus species excluding C. neoformans, however, remains doubtful (Krajden et al., 1991). Although the polysaccharide capsule and CNLAC1, two important virulence factors of $F$. neoformans, are present in most strains of C. podzolicus, the species lacks thermotolerance, the major factor required for successful growth in the tissues of warm-blooded hosts.

All strains of C. podzolicus tested in this study failed to grow at temperatures higher than $30^{\circ} \mathrm{C}$.

Some of the melanin-producing strains previously identified as C. laurentii on the basis of their carbon assimilation profiles showed poor growth at $37^{\circ} \mathrm{C}$ (Kwon-Chung et al., 1992). We attempted to produce experimental infections with such strains but found them unable to survive long enough to cause infection in mouse tissue (data not shown).

The yeasts of Tremella used in this study grew optimally at $25^{\circ} \mathrm{C}$ but failed to grow at temperatures above $30^{\circ} \mathrm{C}$. Yeast cells of $F$. neoformans var. neoformans are most commonly isolated from pigeon droppings throughout the world (Kwon-Chung \& Bennett, 1992). The pigeon body temperature is at least $40{ }^{\circ} \mathrm{C}$ and $\mathrm{F}$. neoformans yeast cells ingested by pigeons survive in the digestive system for a prolonged time (Swinne-Desgain, 1976). The evolution of thermotolerance in this species coupled 
with polysaccharide capsule formation and CNLAC1 activity may have rendered $F$. neoformans a successful pathogen of warm-blooded animals while other heterobasidiomycetous yeasts remained saprophytic.

\section{Conclusion}

F. neoformans is unique among pathogenic yeasts due to the presence of major virulence factors, such as the polysaccharide capsule and the formation of melanin. Although F. neoformans is known to have Tremella lineage and the polysaccharide capsule is a common property produced by many yeasts in the Tremellales, the genetic control of capsule synthesis appears to have diverged. Determination of such genetic diversity will require the molecular dissection of the GXM-capsuleforming genes in the other fungi. The sequence homologous to the CNLAC1 gene that encodes the laccase of $F$. neoformans was found only in C. podzolicus, although several other capsule-forming yeasts reacted weakly to substrates of laccase. The CNLAC1 homologue of C. podzolicus was most closely related to serotypes B/C of F. neoformans, suggesting a common origin. The lack of pathogenicity in C. podzolicus appears to be primarily due to its inability to grow at temperatures equal to or higher than $37^{\circ} \mathrm{C}$.

\section{ACKNOWLEDGEMENTS}

We thank Ashok Varma for reading the manuscript, Lisa Penoyer for her technical assistance and Yun Chang for his assistance in sequence analysis.

\section{REFERENCES}

Abercrombie, M. J., Jons, J. K. N. \& Perry, M. B. (1960). The polysaccharides of Cryptococcus laurentii (Y1401). Can J Chem 38, 2007-2014.

Battacharjee, A. K., Kwon-Chung, K. J. \& Glaudemans, C. P. J. (1978). The structure of the capsular polysaccharide from Cryptococcus neoformans serotype D. Carbohydr Res 73, 183-192.

Boekhout, T., Theelen, B., Diaz, M., Fell, J. W., Hop, W. C. J., Abeln, C. A., Dromer, F. \& Meyer, W. (2001). Hybrid genotypes in the pathogenic yeast Cryptococcus neoformans. Microbiology 147, 891-907.

Chang, Y. C. \& Kwon-Chung, K. J. (1994). Complementation of a capsule-deficient mutation of Cryptococcus neoformans restores its virulence. Mol Cell Biol 14, 4912-4919.

Chang, Y. C. \& Kwon-Chung, K. J. (1998). Isolation of the third capsule-associated gene, CAP60, required for virulence in Cryptococcus neoformans. Infect Immun 66, 2230-2236.

Chang, Y. C. \& Kwon-Chung, K. J. (1999). Isolation, characterization and localization of a capsule associated gene, CAP10, of Cryptococcus neoformans. J Bacteriol 181, 5636-5643.

Chang, Y. C., Penoyer, L. A. \& Kwon-Chung, K. J. (1996). The second capsule gene of Cryptococcus neoformans, CAP64, is essential for virulence. Infect Immun 64, 1977-1983.
Cherniak, R., Jones, R. G. \& Slodki, M. E. (1988). Type-specific polysaccharide of Cryptococcus neoformans. n.m.r.-spectral study of a glucuronomannan chemically derived from a Tremella mesenterica exopolysaccharide. Carbohydr Res 182, 227-239.

Diaz, M. R., Boekhout, T., Theelen, B. \& Fell, J. W. (2000). Molecular sequence analyses of the intergenic spacer (IGS) associated with rDNA of the two varieties of the pathogenic yeast Cryptococcus neoformans. Syst Appl Microbiol 23, 535-545.

Feinberg, A. P. \& Vogelstein, B. (1983). A technique for radiolabeling DNA restriction endonuclease fragments to high specific activity. Anal Biochem 132, 6-13.

Fell, J. W., Boekhout, T., Fonseca, A., Scorzetti, G. \& StatzellTalman, A. (2000). Biodiversity and systematics of basidiomycetous yeasts as determined by large subunit rD1/D2 domain sequence analysis. Int J Syst Evol Microbiol 50, 1351-1371.

Franzot, S. P., Salkin, I. F. \& Casadevall, A. (1999). Cryptococcus neoformans var. grubii: separate varietal status for Cryptococcus neoformans serotype A isolates. J Clin Microbiol 37, 838-840.

Fujimura, H. \& Sakuma, Y. (1993). Simplified isolation of chromosomal and plasmid DNA from yeast. BioTechniques 14, 538-539.

Giardina, P., Cannio, R., Martirani, L., Marzullo, L., Palmieri, G. \& Sannia, G. (1995). Cloning and sequencing of a laccase gene from the lignin-degrading Basidiomycete Pleurotus ostreatus. Appl Environ Microbiol 61, 2408-2413.

Gueho, E., Improvisi, L., Christen, R. \& de Hoog, G. S. (1993). Phylogenetic relationships of Cryptococcus neoformans and some related basidiomycetous yeasts determined from partial large subunit rRNA sequences. Antonie Leeuwenhoek 63, 175-189.

Ikeda, R., Matsuyama, H., Nishikawa, A., Shinoda, T. \& Fukazawa, Y. (1991). Comparison of serological and chemical characteristics of capsular polysaccharides of Cryptococcus neoformans var. neoformans serotype A and Cryptococcus albidus var. albidus. Microbiol Immunol 35, 125-138.

Krajden, S., Summerbell, R. C., Kane, J. \& 7 other authors (1991). Normally saprobic Cryptococci isolated from Cryptococcus neoformans infection. J Clin Microbiol 29, 1883-1887.

Kwon-Chung, K. J. (1975). Description of a new genus, Filobasidiella, the perfect state of Cryptococcus neoformans. Mycologia 67, 1197-1200.

Kwon-Chung, K. J. \& Bennett, J. E. (1992). Medical Mycology, pp. 397-446. Philadelphia: Lea \& Febiger.

Kwon-Chung, K. J., Polacheck, I. \& Popkin, T. J. (1982). Melaninlacking mutants of Cryptococcus neoformans and their virulence for mice. J Bacteriol 150, 1414-1421.

Kwon-Chung, K. J., Wickes, B. L., Stockman, L., Roberts, G. D., Ellis, D. \& Howard, D. H. (1992). Virulence, serotype, and molecular characteristics of environmental strains of Cryptococcus neoformans var. gattii. Infect Immun 60, 1869-1874.

Kwon-Chung, K. J., Chang, Y. C., Bauer, R., Swann, E. C., Taylor, J. W. \& Goel, R. (1995). The characteristics that differentiate Filobasidiella depauperata from Filobasidiella neoformans. Stud Mycol 38, 67-79.

Mikuni, J. \& Morohoshi, N. (1997). Cloning and sequencing of a second laccase gene from the white-rot fungus Coriolus versicolor. FEMS Microbiol Lett 155, 79-84.

Nakamura, Y., Kano, R., Watanabe, S. \& Hasegawa, A. (2000). Molecular analysis of CAP59 gene sequences from five serotypes of Cryptococcus neoformans. J Clin Microbiol 38, 992-995.

Oberwinkler, F. (1987). Heterobasidiomycetes with ontogenetic 
yeast-stages - systematics and phylogenetic aspects. Stud Mycol 30, 61-74.

Peláez, F., Martínez, M. J. \& Martínez, A. T. (1995). Screening of 68 species of basidiomycetes for enzymes involved in lignin degradation. Mycol Res 99, 37-42.

Perry, C. R., Smith, M., Britnell, C. H. \& Wood, D. A. (1993). Identification of two laccase genes in the cultivated mushroom Agaricus bisporus. J Gen Microbiol 139, 1209-1218.

Polacheck, I., Hearing, V. I. \& Kwon-Chung, K. J. (1982). Biochemical studies of phenoloxidase and utilization of catecholamines in Cryptococcus neoformans. J Bacteriol. 150, 1212-1220.

Rhodes, J. C., Polacheck, I. \& Kwon-Chung, K. J. (1982). Phenoloxidase activity and virulence in isogenic strains of Cryptococcus neoformans. Infect Immun 36, 1175-1184.

Salas, S. D., Bennett, J. E., Kwon-Chung, K. J., Perfect, J. R. \& Williamson, P. R. (1996). Effect of the laccase gene, CNLAC1, on virulence of Cryptococcus neoformans. J Exp Med 184, 377-386.

Slodki, M. E. (1966). Hydrolysis products from an extracellular Tremella polysaccharide. Can J Microbiol 12, 495-499.
Staib, F. (1962). Cryptococcus neoformans and Guizotia abyssinica (Syn. G. oleifera D.C.). Z Hyg 148, 466-475.

Swann, E. C. \& Taylor, J. W. (1993). Higher taxa of Basidiomycetes: an 18S rRNA gene perspective. Mycologia 85, 923-936.

Swinne-Desgain, D. (1976). Cryptococcus neoformans in the crops of pigeons following its experimental administration. Sabouraudia 14, 313-317.

Varma, A. \& Kwon-Chung, K. J. (1991). Rapid method to extract DNA from Cryptococcus neoformans. J Clin Microbiol 30, 2960-2967.

Williamson, P. R. (1994). Biochemical and molecular characterization of the diphenol oxidase of Cryptococcus neoformans: identification as a laccase. J Bacteriol 176, 656-664.

Xu, J. P. (2000). Multiple gene genealogies reveal recent dispersion and hybridization in the human pathogenic fungus Cryptococcus neoformans. Mol Ecol 9, 1497-1481.

Received 5 February 2001; revised 11 April 2001; accepted 20 April 2001. 